\title{
Rotating Disc Apparatus and its application to estimate sediment erosion in Hydro turbines
}

\author{
Oblique Shrestha ${ }^{1}$, Hari Prasad Neopane ${ }^{2}$, BholaThapa ${ }^{2}$, Young-Ho Lee ${ }^{3}$, Aman Kapali ${ }^{1}$ \\ 'Turbine Testing Lab, Department of Mechanical Engineering, Kathmandu University (KU), Dhulikhel, Nepal \\ ${ }^{2}$ Department of Mechanical Engineering, KU, Dhulikhel, Nepal \\ ${ }^{3}$ Division of Mechanical Engineering, Korea Maritime and Ocean University, Busan, Korea \\ * Corresponding author hari@ku.edu.np
}

\begin{abstract}
Article Info

Volume 8, Issue 6

Page Number : 348-358

\section{Publication Issue}

November-December-2021

\section{Article History}

Accepted : 01 Dec 2021

Published : 12 Dec 2021

The removal of surface material due to repeated impacts of sediment is known as sediment erosion. This prominent phenomenon is found to exist on a run of the river types of hydro projects where the hydro turbines are exposed to sediment particles. It has drawn the attention of researchers, academic institutions, and hydropower developers to conduct research on this issue. Investigation of the problem at the site may require sophisticated equipment and sensors- set up for quantitative measurements. This process is time consuming and difficult as it is difficult to access the erosion location. Laboratory setup can be a solution to study and investigate erosion behaviour in well-controlled laboratory conditions. Among several erosion testing apparatuses, Rotating Disc Apparatus (RDA) has been used for the investigation of erosion as well as cavitation of hydro components, and to study the erosion resistivity of different materials. This device mainly consists of a rotating disc and an electric motor, which is used to rotate a disc-holding specimen. This paper evaluates the RDA for its applicability in simulating the flow on the surfaces of the components of the hydro turbines as that occurs in actual hydro power plants. The outcomes from the present study indicated that RDA produces promising erosion results and can simulate the wear conditions.

Keywords : Sediment erosion, RDA, Hydro Turbine, Numerical analysis, Experimental analysis
\end{abstract}

\section{INTRODUCTION}

Sediment erosion in hydraulic machinery was and still is a main academic and engineering concern in the field of hydraulic machinery. It is a challenging task to assess the effects of sediment erosion due to complex and simultaneously occurring interaction between several erosion influencing parameters such as sediment concentration, impingement angle, the velocity of flow, characteristics of abrasive materials 
[1]. It can be found in the literature, for erosion studies, three different approaches are adopted for erosion studies: (a) numerical or simulation studies (b) case studies and (c) experimental studies. Simulation tests are widely adopted for the prediction of erosion numerically with the help of different erosion models, and for flexible and precise control of variables. Validation of the obtained results, however, has become a challenging task especially in terms of nature and quantification. The efficiency and performance of the turbine are studied in actual prototype hydropower plants using the case study approach. These types of studies are carried out in natural settings and thus, quantitative measurement of erosion is difficult and time-consuming. However, the actual conditions on the field can be simulated by performing a series of tests, replicating the existing operating parameters in a well-designed laboratory test rig. Generally, accelerated erosion tests are performed in precisely controlled laboratory conditions to shorten the test period over the low rates of erosion that takes place in the actual environment. In this paper, the development of an erosion testing apparatus by various researchers has been studied. It also presents the application and future of Rotating Disc Apparatus (RDA) as an erosion tester to evaluate abrasion and cavitation erosion in hydro turbines.

The erosion process is a complex phenomenon that is mainly due to (a) fluid flow conditions (velocity of flow, particles impingement angle, particles concentrations, density, temperature) (b) particles characteristics like size, shape, hardness, strength and (c) properties of target materials like mechanical properties (toughness, yield and ultimate strength), work hardening, microstructures, elasticity, surface topography [1]. However, replications of wear simulation in a lab environment can be closely correlated if the right selection of accelerator wear apparatus is adopted based on the factors such as the motion of test specimen, target materials and properties, erodent type, pressure and speed applied
[2]. These types of laboratory tests are purposely designed to accelerate the wear rate of test specimens to obtain results in a short period within an environment, which need to be controlled as well as monitored [3]. The outcome of the test is then analyzed to make predictions about the useful service life and maintenance interval of the component [4]. In case of erosion testing by solid particle impingement, normally the velocity of impact particles or concentration of the abrasives, density of the abrasives is amplified to obtain rapid erosion results. However, it should be kept in mind that the acceleration processes do reproduce the true wear mechanism.

\section{LITERATURE ON LABORATORY EROSION TESTING APPARATUS}

Numerous designs of erosion test rigs are in use to study the erosion phenomenon that occurs in hydropower plants. These can be classified upon the process of injecting erodent particles into the test chamber and expelling it out of the system after striking the test specimen. Further, these rigs are categorized into different types based on the motion of test specimens relative to the motion of fluid: (a) Rotary type test rigs, which further include Slurry pot, Rotating Disc Apparatus, Whirling arm and Coriolis type (b) Jet- type test rigs.

\section{Jet type test rigs}

For slurry erosion experiments, jet type test rigs have been commonly used to study the performance of hydraulic turbines and materials [5] [6] [7] [8] Based on the jet velocity, a high-velocity erosion test rig and lower velocity erosion test rig [5] are respectably the ones in which erosion caused at velocities greater than $6-9 \mathrm{~m} / \mathrm{s}$ [9] [10] [11] [12] and less than $6 \mathrm{~m} / \mathrm{s}$ is examined. Further, jet type test rigs can be categories into re-circulating type (RC) and non-recirculating type (NRC).

Jet type test rigs can provide better parameter variation and control. However, in the case of stationary specimen types, the slurry jet is locally 
concentrated on the specimen and the impingement angle of all abrasive particles may deviate during the test. Regular monitoring of the nozzle must be done to ensure no wear due to high impact velocity.

\section{Slurry pot test rigs}

This type has a very simple design and is generally used for ranking the erosion resistance for different materials [13] as well as to evaluate the erosion behaviour of materials [14]. The results from the pot tests were reported to agree with the pipelining wear [15]. This test setup facilitates the multiple tests of the samples at a time. However, the unstable flow of the slurry makes measurement and control of the velocity and impingement angle accurately. Also, the slurry degradation by fracturing and rounding of solid particles affects the erosion rate along with the test duration. Moreover, the uniform distribution of the slurry mixture is difficult to achieve throughout the vertical cross-section of the cylindrical pot. Further, complex flow conditions make it complicated to study the effect of erodent characteristics such as size, shape, and abrasiveness on erosion rate.

\section{Whirling arm test rigs}

This test rig developed by Lin and Shao [16] comprises mainly three units: a slurry unit, specimen rotation unit, and a vacuum unit. The test specimens, rotated by the electronically controlled motor are impinged by dropping slurry inside the vacuum chamber to eliminate the error caused by the airflow effect of the particles [17]. Further, a photoelectric velocity meter is used to measure the impact velocity with an error $<2 \%$ in the range of $10-70 \mathrm{~m} / \mathrm{s}$. This test rig can be used to simulate the erosion of a Pelton runner as the slurry jet strikes the rotating specimen in which velocity of the jet and impingement angle can be measured and controlled accurately.

\section{Coriolis test rigs}

This type of test apparatus was developed by Tuzson [18], to investigate the slurry erosion interaction between the surfaces as in slurry pumps and stationary flow passages like pipelines. The use of this device facilitates erosion resistance comparisons of different materials tested with different concentrations by calculating the specific energy required for material removal with the known volume of wear [19]. These test rigs can be extensively used for solid impingement tests of materials impacting at a very low impingement angle. Such tests have been carried out to compare laboratory results with field results of components such as slurry pumps [20] [21].

\section{RDA APPLICATION IN HYDRAULIC MACHINERY RESEARCH}

Initially, the experiment was carried out in RDA to study the factors affecting cavitation [22][23]. Similarly, Wood et al. [24] conducted experiments in RDA refractory metal alloys for the impellers operating at high suction specific speeds to investigate cavitations' damage resistance. It was observed that the flow field in RDA closely resembles the operating conditions of pumps. With the use of RDA, Shima et al. [25] evaluated cavitation damage resistance of stainless steel over a high peripheral speed range of $65-77 \mathrm{~m} / \mathrm{s}$. The outcome of the experiment was that the damage due to cavitation tends to increase with an increase in the peripheral speed as indicated by the velocity exponent. Mann [26] performed experiments to analyze the cavitation erosion and abrasion erosion resistance of coatings using RDA. The results suggested that the coated material having higher ultimate tensile strength and hardness showed poorer resistance in cavitation erosion but has improved abrasion resistance. Later, Mann [27] WC+12Co coating appears to be effective. Likewise, $\mathrm{RDA}$ has been used to study the combined effect of sand erosion and cavitation erosion at a velocity value of $39 \mathrm{~m} / \mathrm{s}$ [28] It was visually observed that the combined effect of sand erosion and cavitation erosion is more than the sum of their individual 
effects. Ceramic coating applied with High Velocity Oxygen Fuel (HVOF) process is found to have better erosion resistance in cavitation erosion, sand erosion and also of their combined effect.

Rajkarnikar et al. [29] developed an RDA set up to investigate sediment erosion effects on two different to compare the effects of sediment erosion effect on designs of blades of Francis Turbine. A scale down model of Francis casted blades were used as test specimens that were maintained at an angle, which represents the actual inlet flow conditions of the

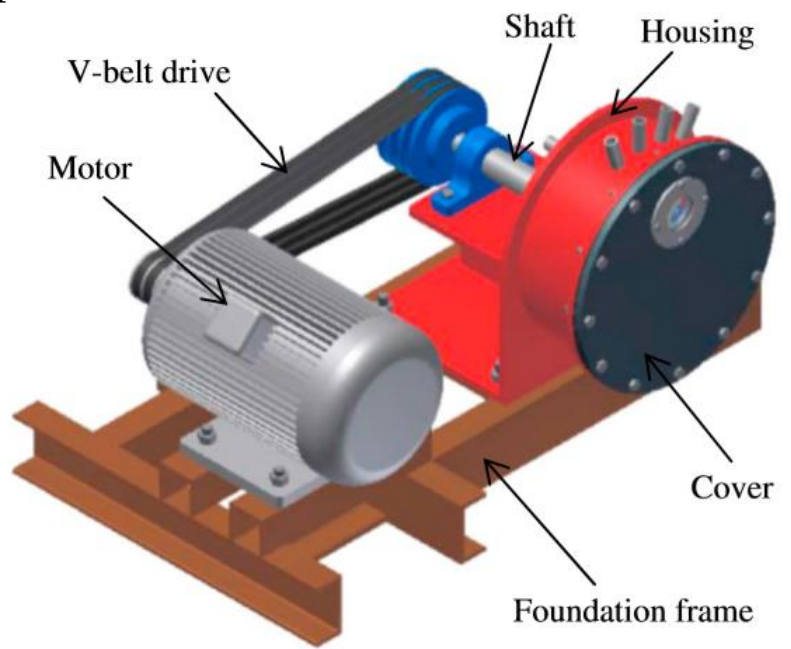

Francis turbine as represented in Figure 1. A closed housing filled with a mixture of water and sediment is used for a rotating disc driven by a motor and holding four test blades. The test blades are mounted on the rotating disc. The test was performed for 30 minutes in a single on painted specimens to study wear patterns by observing the removal of paint on the surface of the test specimens. The weight-loss method was used to estimate the rate of material removal from the surface of specimens of two alternative blade designs.

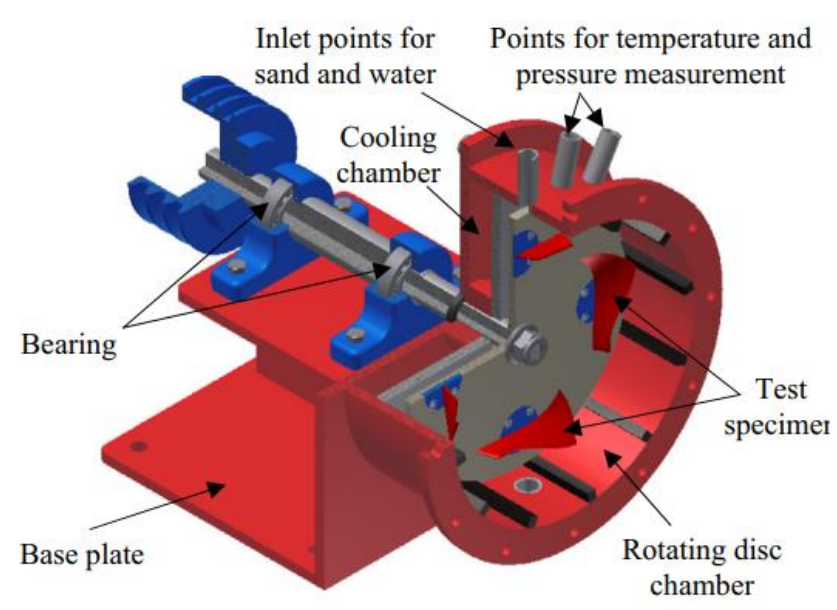

Figure 1: 3D view of RDA (Adopted from Rajkarnikar et al [29])

Figure 2 shows the observation of erosion patterns on observed in the turbines operating in the power the specimen in which the location of paint removal plants along with the patterns predicted by numerical was found to be identical with the pattern of wear studies using CFD.

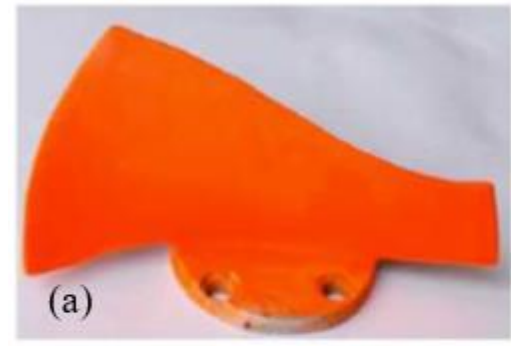

(b)
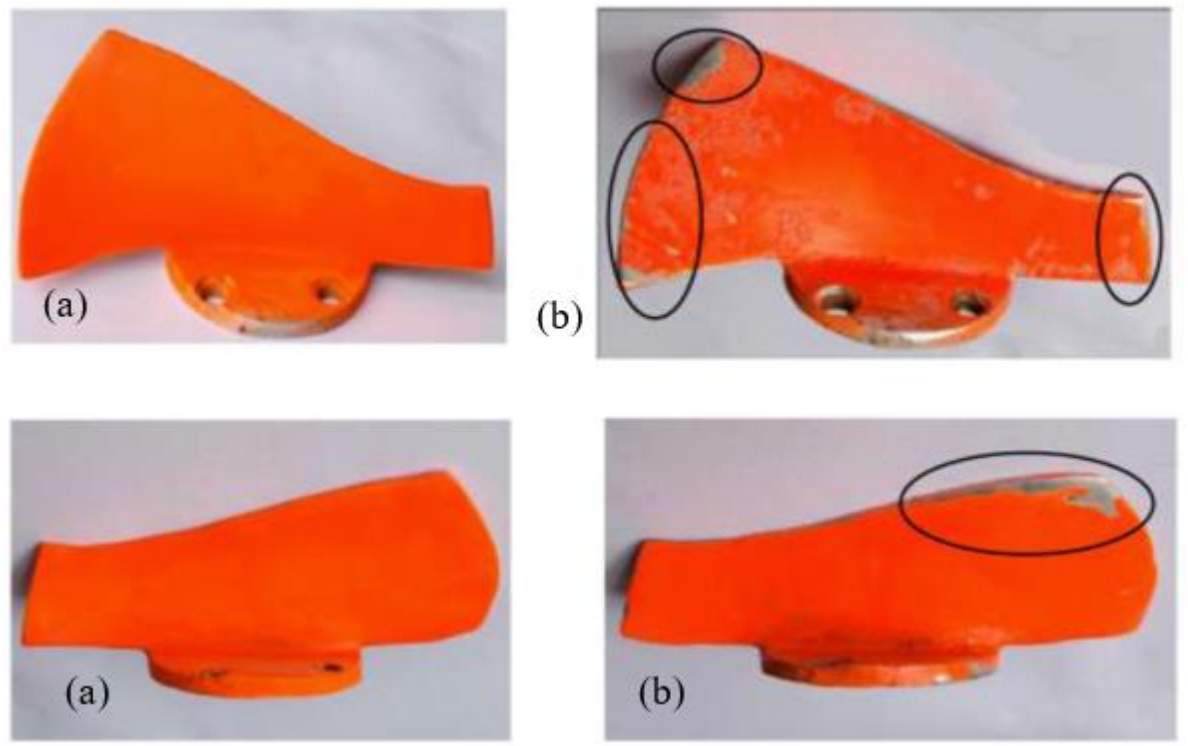
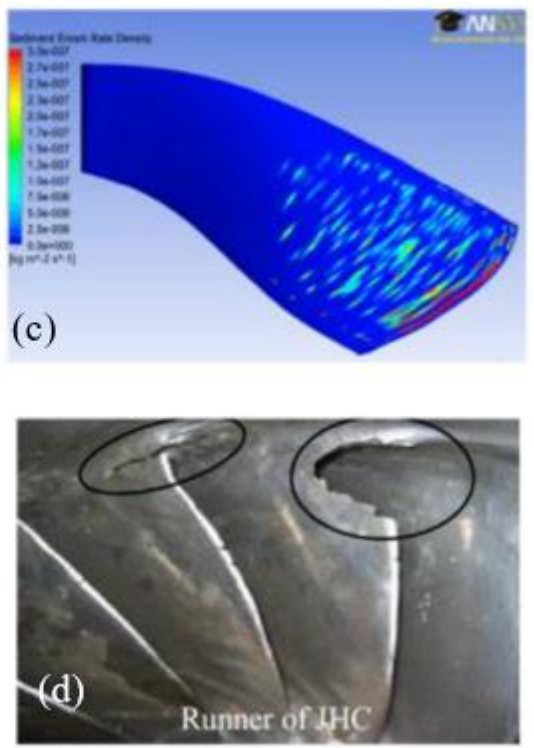

Figure 2 : Observation of erosion patterns (a) test specimen before test (b) test specimen after 30min (c) result of CFD analysis (d) eroded runner of JHC. Adapted from Rajkarnikar et al.[29] 
Figure 3 shows the eroded blade after 125 and 350 minutes of slurry exposure. At the earlier stages, the erosive nature of wear was observed while the erosion followed by cavitation was predominant as the experiment continued. The erosion rate measurements of reference design (A1) and optimized
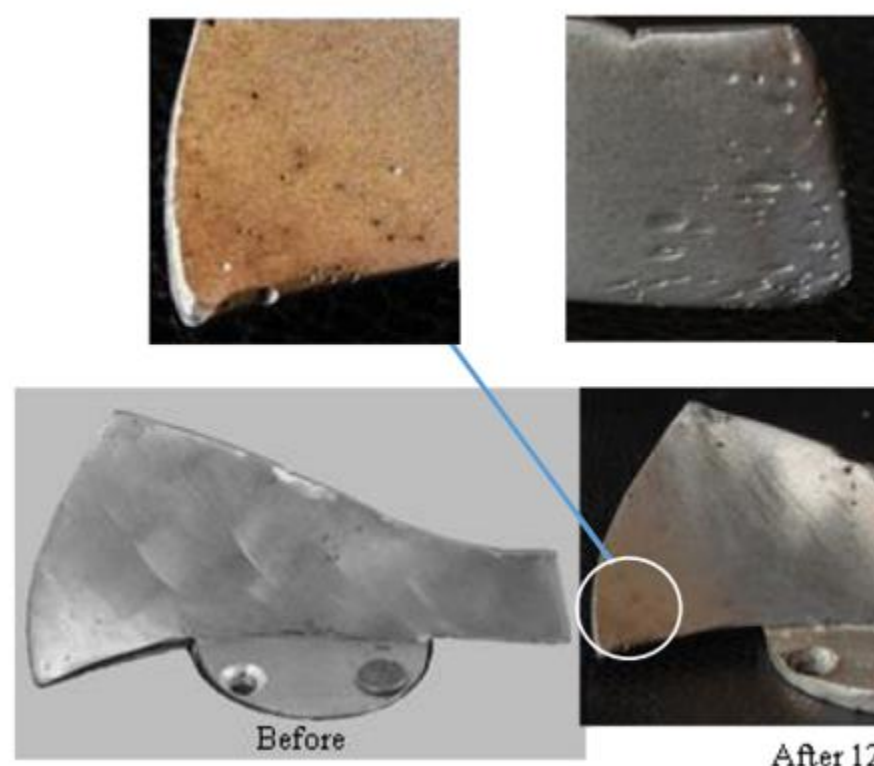

design (A2) is shown in Figure 4. It is apparent that the optimized design was considerably able to reduce the rate of erosion as compared to the reference design.

Figure 3: Observation of wear pattern in the test specimen
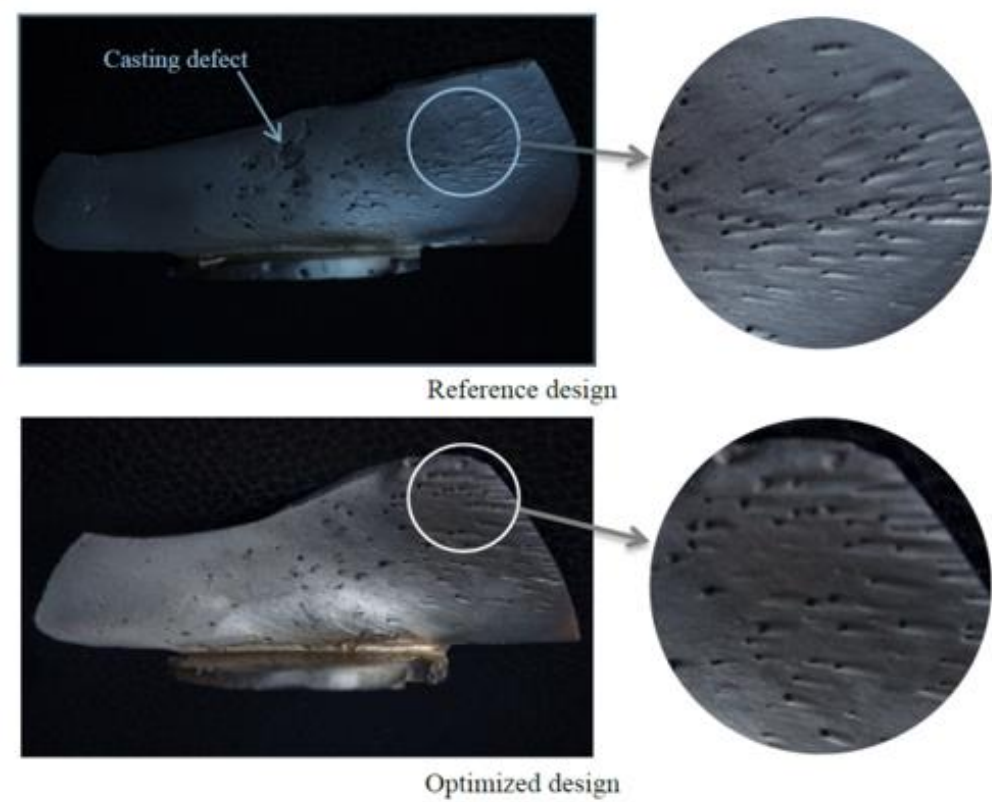

Figure 4: Combined effect of erosion and cavitation in test specimen [29]

Later, several design modifications were made on RDA by Shrestha et al. [22] and installed the test rig at Turbine testing lab (TTL), Kathmandu University and for PIVLAB, Korea Maritime and Ocean
University (KMOU) to investigate sediment erosion and wear patterns on blades of Cross-flow turbine (CFT) T- 15 model. Four numbers of mild steel blades were fabricated and were clamped at the edge of the 
disc as presented in Figure 5. The experiment was conducted at a sand concentration of $82,000 \mathrm{ppm}$ which would require $650 \mathrm{~g}$ of sand in a single run. Testing was performed with a sediment size range of 150-200 $\mu \mathrm{m}$. Numerical analyses were conducted under similar operating conditions as in RDA, and the wear patterns observed were in close agreement.

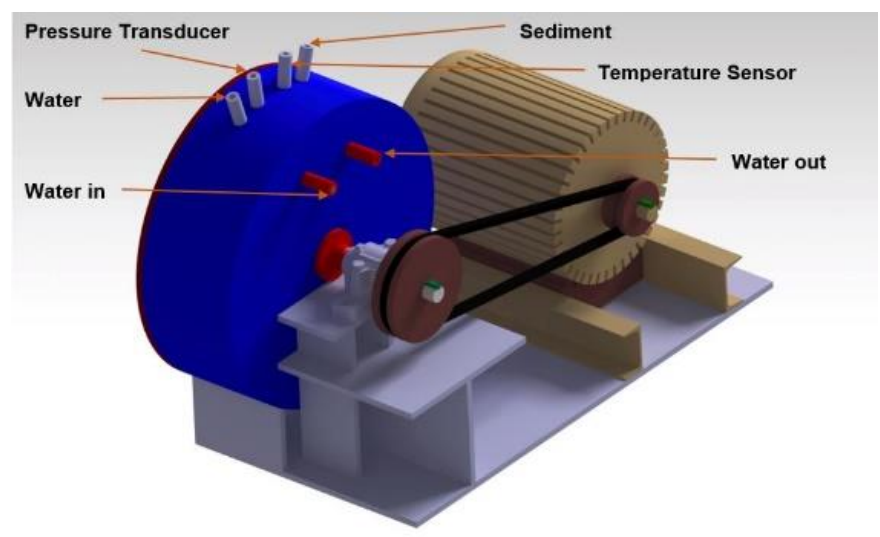

Table 1: Measured weight of the blade in an experiment [Adopted from Park et al. [31])

\begin{tabular}{|c|c|c|c|c|c|c|c|}
\hline Test Material & Before test & $\begin{array}{c}1^{\text {sttest }} \\
(100 \mathrm{~min})\end{array}$ & $\begin{array}{c}2^{\text {nd }} \text { test } \\
(200 \mathrm{~min})\end{array}$ & $\begin{array}{c}3^{\text {rd test }} \\
(300 \mathrm{~min})\end{array}$ & $\begin{array}{c}4^{\text {th test }} \\
(400 \mathrm{~min})\end{array}$ & $\begin{array}{c}5^{\text {th test }} \\
(500 \mathrm{~min})\end{array}$ & $\begin{array}{c}6^{\text {thtest }} \\
(600 \mathrm{~min})\end{array}$ \\
\hline & & $198.67 \mathrm{~g}$ & $198.58 \mathrm{~g}$ & $198.51 \mathrm{~g}$ & $198.44 \mathrm{~g}$ & $198.37 \mathrm{~g}$ & $198.29 \mathrm{~g}$ \\
\hline $\mathrm{Cr}$ & $185.70 \mathrm{~g}$ & $185.67 \mathrm{~g}$ & $185.63 \mathrm{~g}$ & $185.61 \mathrm{~g}$ & $185.57 \mathrm{~g}$ & $185.55 \mathrm{~g}$ & $185.52 \mathrm{~g}$ \\
\hline Cr(coated Ni) & $195.94 \mathrm{~g}$ & $195.92 \mathrm{~g}$ & $195.89 \mathrm{~g}$ & $195.88 \mathrm{~g}$ & $195.85 \mathrm{~g}$ & $195.83 \mathrm{~g}$ & $195.81 \mathrm{~g}$ \\
\hline
\end{tabular}

Koirala [24] used the same RDA developed by Shrestha [22] to perform an erosion test for different NACA profiles of the guide vane of the Francis turbine. The vane tip velocity of $6 \mathrm{~m} / \mathrm{s}$ was selected on a disc of $250 \mathrm{~mm}$ diameter with an rpm of 458 . The arrangement of profiles on the disc is illustrated in Figure 6(a). Experiments were performed at $3 \mathrm{GV}$ angles; P1, P2 and P3 as shown in Figure 6(b). Figure

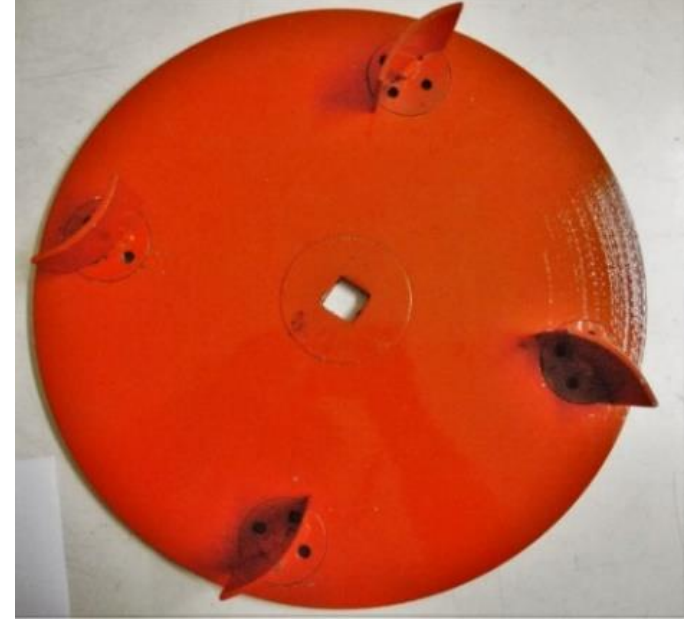

Figure 5: (a) Rotating disc apparatus 3D modelling and (b) disc with CFT blade test specimens Adopted from Shrestha [30]

Park et al. [23] performed an experiment on CFT blades, made of three different materials; SUS304 grade stainless steel, high hardness chrome steel and chrome steel coated with nickel. The test was run at an interval of 100 minutes with a total of 600 minutes and the weight of the specimens was measured after every 100 minutes as enumerated in Table 1 . It was observed that the chrome and nickel coated on the specimen surface significantly reduced the abrasion erosion than that of the blade made up of stainless steel. 6(c) and (d) shows the arrangement and construction in RDA. The epoxy-based paint was sprayed on the test specimens made with aluminum material to observe the location of erosion. The sediment size ranging from $150-300 \mu \mathrm{m}$ with a concentration of $66.67 \mathrm{~g} / \mathrm{l}$ was maintained to conduct the experiment. It was observed that the trend in erosion patterns (see Figure 7) is matches with simulation results. 

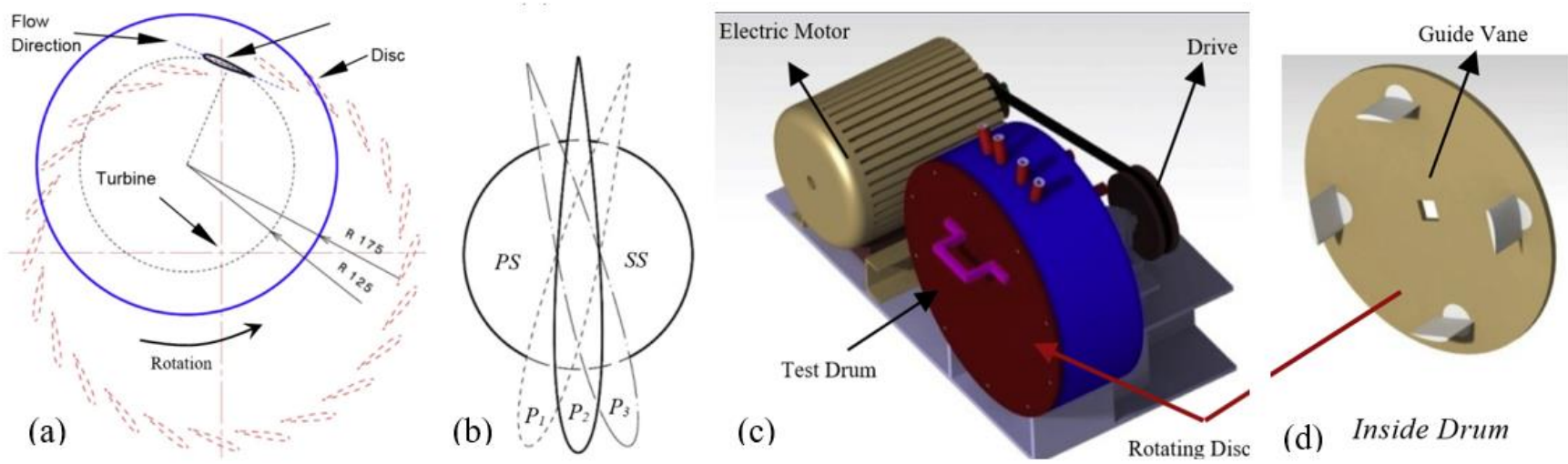

Figure 6: RDA used for erosion test in guide vane of Francis turbine. Adopted from Koirala et al. [32]

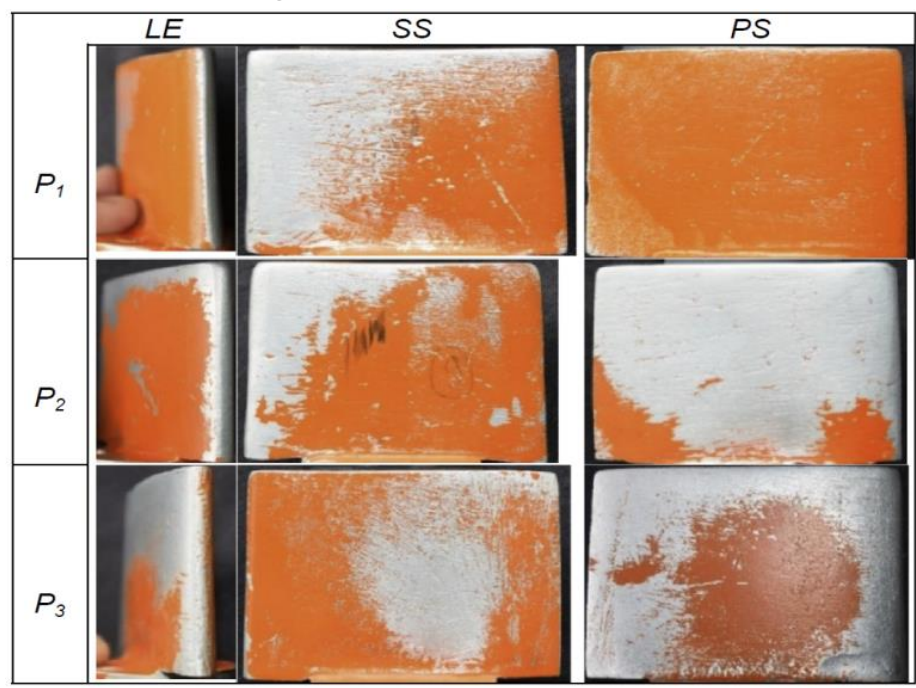

Figure 7: Observation of erosion pattern using paint indication technique. Adopted from Koirala et al. [32] Similarly, a series of tests were performed at an NACA 4412 has a lower material removal rate, and interval of 30 minutes with a total of 90 minutes for performs relatively better performance when exposed the selected NACA profiles test specimens as to sediment particles. presented in Figure 8 . The study concluded that
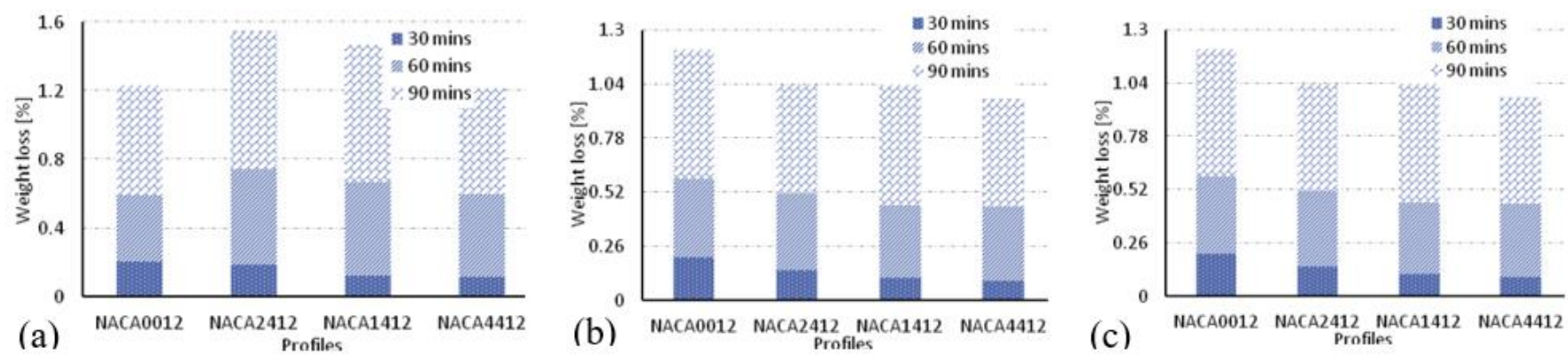

Figure 8 : Weight loss \% of guide vane at (a) mid-position (P2), (b) towards closing (P1) (c) toward opening (P3) specimen was enamel coated with four different

Gantawa [25] also used the same RDA developed by Shrestha et al. [22] to analyze the erosion potential of different sized sediment particles collected from the Budhi-Gandaki-Trishuli river of Nepal. The test layers of colours (blue, red, yellow and green on the top) respectively. Figure 9 Error! Reference source not found. illustrates wear patterns and the amount of erosion observed on test specimens during the experiments. From the experimental observations, it 
was found that the abrasion rate increases with an increase in angularity and quartz content in the

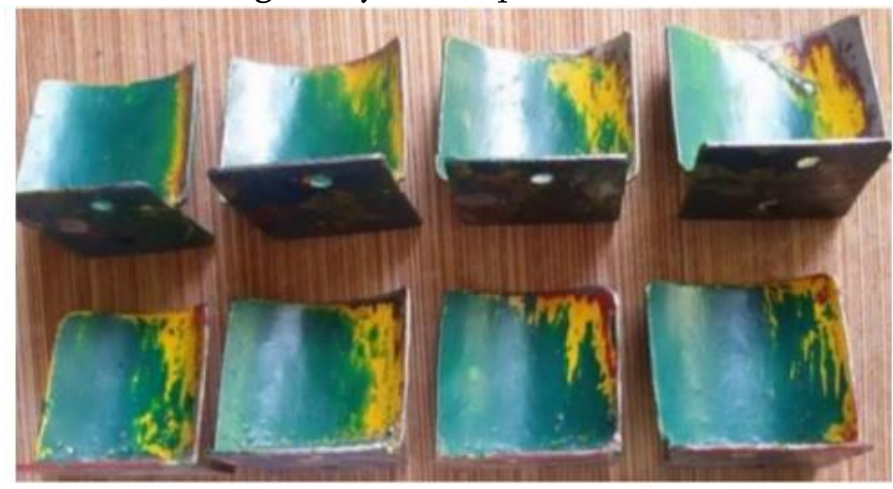

(a) sediment particles.

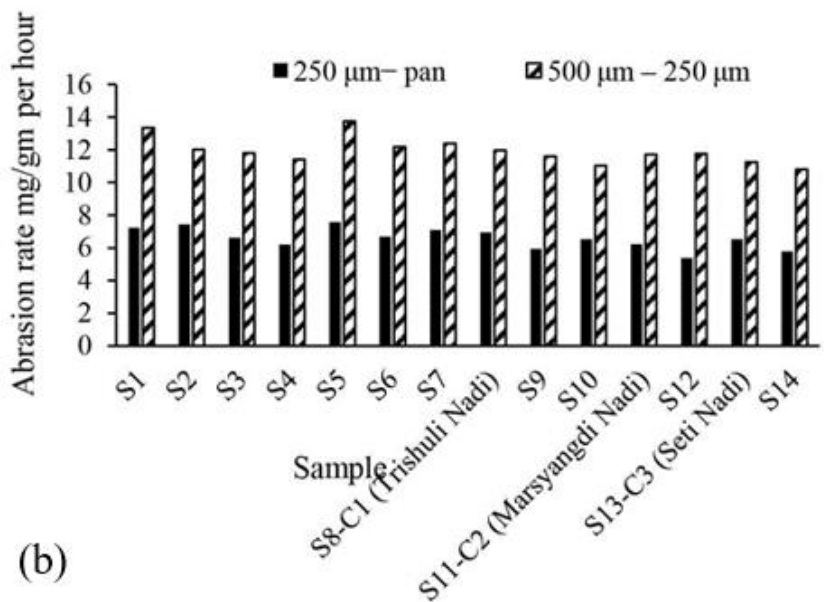

Figure 9: (a) Test specimen after abrasion test (b) Abrasion rate observed on a different sample. Adopted from Gantawa [33]

\section{The flow field in RDA}

The numerical analysis was carried out to investigate whether the flow field in RDA can simulate the flow field as in CFT. For this study, the fluid domain of RDA and CFT was modelled in CATIA V5 (Student Version) and the structured hex mesh was created (See Figure 10). The mesh dependence study was carried out for both domains. The SST turbulence model was chosen as it can predict field flow in both of the above-mentioned cases, RDA and CFT, with better precision and less time consumption [34] [35].
The flow inlet and exit boundary conditions are used in CFT where a no-slip wall is defined at stationary (a pipe, diffuser, stator up and stator down) and rotating (runner) components of the domain. The mass flow inlet is defined at the pipe and the average static pressure exit is defined at stator down. Since the RDA is an enclosed type domain, normal boundary conditions cannot be applied. The domain is filled with a mixture of sediment and water and a no-slip wall is defined at stationary (stator with fins) and rotating (rotor with attached blade) components.
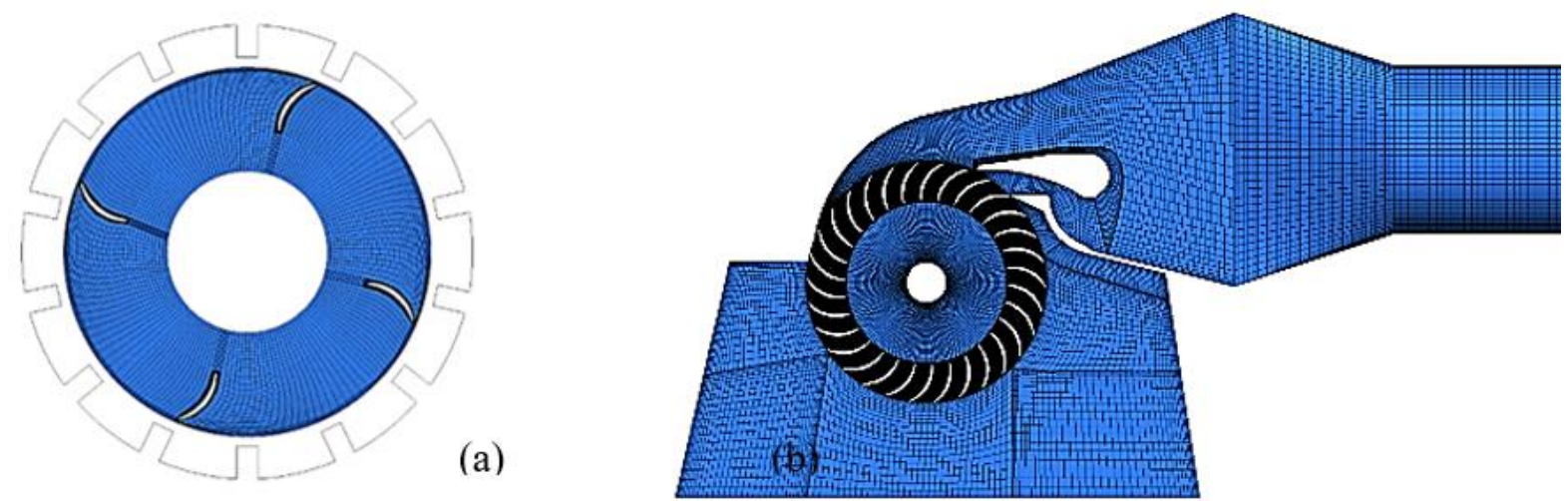

Figure 10 : ICEM hex mesh of (a) RDA (b) CFT

the water flow vector in CFT and RDA exhibits an

Figure 11 shows the velocity plot of RDA and CFT. It can be observed that the water flows with a similar velocity pattern, entering the leading edge on the pressure side and suction side of the blade. Similarly, identical flow pattern along the blade and at the trailing edge. The entrained water flow in between the blades of the CFT can be observed whereas flow separation takes place intermittently in RDA. Further 
in RDA, a vortex is created in between two specimens clamped as can be seen in Figure 11(b). It may have occurred due to the fact that, for the same outside diameter, the runner of CFT is equipped with 30 numbers of blades while only 4 numbers of the test specimens are clamped on the rotating disc of RDA. Further, the runner of the CFT rotates when water

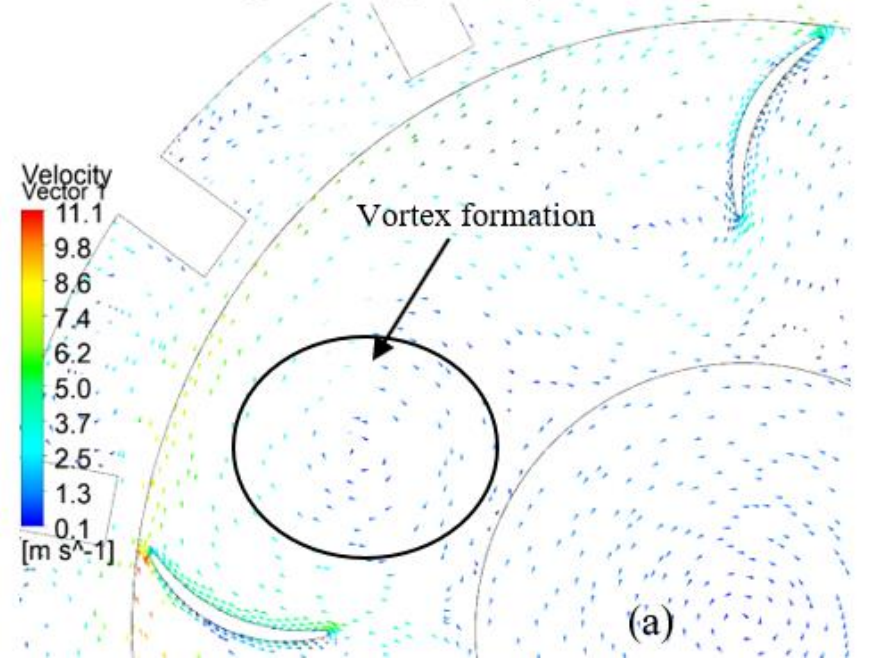

strikes the leading edge of the blades of the runner while in $\mathrm{RDA}$; the test blade is rotated with a motor connected with the shaft. Figure 12 shows the pressure plot of CFT and RDA. It can be seen that the pressure at the inlet and outlet of the blades for CFT and RDA is almost identical.

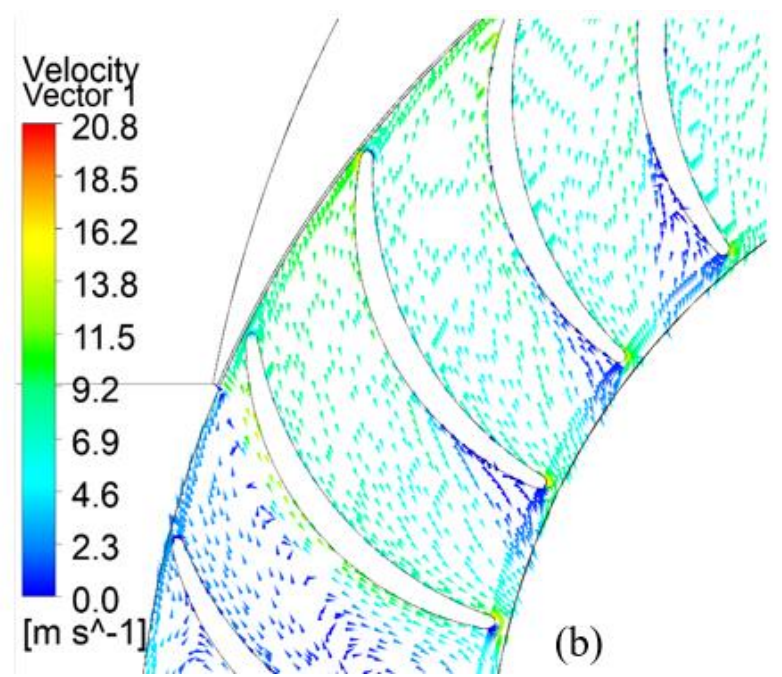

Figure 11: Velocity distribution (a) RDA (b) CFT
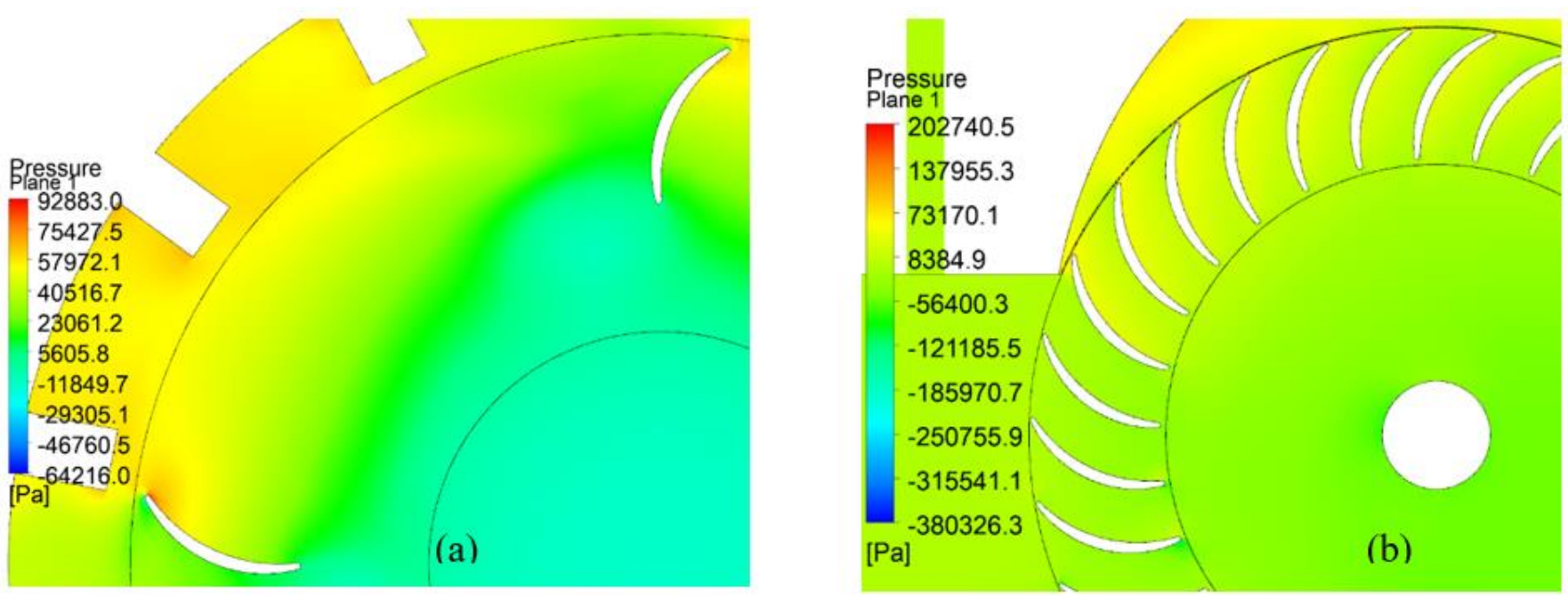

Figure 12: Pressure distribution (a) RDA (b) CFT

\section{v. CONCLUSION}

This paper intends to evaluate the suitability of the RDA to estimate, visualize and quantify the wear on the components of hydraulic turbines. Although RDA yields result in comparatively less time, the hydraulics of flow in CFT and RDA is found to be different examined with numerical analysis and results obtained using RDA might be misleading. The severity of erosion in the numerical and experimental study are not identical, still, when comparisons are made among the alternative test specimens' profiles, the results of both studies comply with each other. The selection of a guide vane profile is possible through experiments on scale down models in RDA. $\mathrm{RDA}$ is found to be capable of determining the 
erosion resistivity of different materials tested under similar operating conditions. Besides, the cavitation study can be performed with some modifications in RDA. Therefore, there is a good opportunity to establish $\mathrm{RDA}$ as a promising erosion testing apparatus in the laboratory if the test setup is improved further.

\section{REFERENCES}

[1]. B. Thapa, "Sand erosion in hydraulic machinery," Norwegian University of Science and Technology, Norway, 2004.

[2]. Helle A, Andersor P, Ahlroos T, Kupiainen V, "Erosive wear of coatings and methods to moniter coating wear- a literature study," 2004.

[3]. Axen N, Hogmark S, Jacobson S, Friction and wear measurement techniques, CRC Press LLC, 2001.

[4]. T. N, "Estimation of repair cycle of turbine due to abrasion caused by suspended sand and determination of desilting basin capacity," in International seminar on sediment handling technique, Kathmandu, Nepal, 1999.

[5]. Zu J.B, Hutchings I.M, Burstein G.T, "Design of a slurry erosion test rig," Wear, vol. 140, pp. 331-344, 1990.

[6]. Lin H.C, Wu S.K, Yeh C.H, "A comparison of slurry erosion characteristics TiNi shape memory alloys and SUS 304 Stainless steel," Wear, vol. 249, pp. 557-565, 2001.

[7]. Burstein G.T, Sasaki K, "Effect of impact angle on the slurry erosion corrosion of 304L stainless steel," Wear, vol. 240, no. 1-2, pp. 80-94, 2000.

[8]. Chauhan A.K, Goel D.B, Prakash S, "Erosion behavior of hydro turbine steels," Bull. Mater. Sci, vol. 31, no. 2, pp. 115-120, 2008.

[9]. Thapa B, Brekke H, "Effect of sand particle size and surface curvature in erosion of hydraulic turbine," in In IAHR Symposium on Hydraulic Machinery and Systems, Stockholm, 2004.

[10]. Grewal H.S, Agrawal A, Singh H, "Slurry erosion mechanism of hydroturbine steel: Effect of operating parameters," Tribology letters, vol. 52, pp. 287-303, 2013.

[11]. Khurana S, Varun , Kumar A, "Effect of silt particles on erosion of Turgo impulse turbine blades," International Journal of Ambient Energy, vol. 35, no. 3, pp. 155-62, 2014.

[12]. Padhy M.K, Saini R.P, "Study of silt erosion mechanism in Pelton turbine buckets," Energy, Elsevier, vol. 39, no. 1, pp. 286-293, 2012.

[13]. Gandhi B.K, Singh S.N, Seshadri V, "A study on the effect of surface orientation on erosion wear of flat specimens moving in a solid-liquid suspension," Wear, vol. 254, pp. 1233-1238, 2003.

[14]. Lathabai S, Pender D.C, "Microstructural influence in slurry erosion of ceramics," Wear, vol. 189, pp. 122-13, 1995.

[15]. Gupta R, Singh S.N, Sehadri V, "Prediction of uneven wear in a slurry pipelines on the basis of measurements in a pot tester," Wear, vol. 184, pp. 169-178, 1995.

[16]. Lin F.Y, Shao H.S, "1991," Effect of impact velocity on slurry erosion and a new design of a slurry erosion tester, vol. 143, no. 2, pp. 231240, 1991.

[17]. Bukhaiti M.A, Ahmen S.M, Badran F.M.F, Emara K.M, "Effect of impingement angle on slurry erosion behavior and mechanisms of 1017 steel and high-chromium white cast iron," Wear, vol. 262, pp. 1187-1198, 2007.

[18]. T. J.J, "Laboratory slurry erosion tests and pump wear rate calculations," Journal of Fluids Engineering, vol. 106, no. 2, pp. 135-140, 1984.

[19]. Clark HMcl, Tuzson J, Wong K.K, "Measurement of specific energies for erosive wear using a Coriolis erosion tester," Wear, vol. 241, pp. 1-9, 2000.

[20]. Llewellyn R.J, Yick S.K, Dolman K.F, “Scouring erosion resistance of metallic materials used in slurry pump service," Wear, vol. 256, pp. 592599, 2004.

[21]. Walker C.I, Robbie P, "Comparison of some laboratory wear tests and field wear in slurry pumps," Wear, vol. 302, pp. 1026-1034, 2013. 
[22]. O. Shrestha, N. Acharya, B. Thapa, H.P. Neopane, Y.H. Lee, "Design and Development of Rotating Disc Apparatus to Test Sediment Erosion in Cross Flow Turbine Runner Blades," in Proceedings of the International Symposium on Current Research in Hydraulic Turbines, Turbine Testing Lab, Kathmandu University, Dhulikhel, Nepal, 2016.

[23]. J. H. Park, d. h. Lee, S. J. Cha and Y. H. Lee, "Development of a sediment Erosion-Proof Micro Class Cross-Flow Hydro Turbine," in Precedings of the International Symposium on Current Research in Hydraulic Turbines, Dhulikhel, 2016.

[24]. R. Koirala, . H. P. Neopane, O. Shrestha, B. Zhu and B. Thapa, "Selection of guide vane profile for erosion handling in Francis Turbines," Renewable Energy, vol. 112, pp. 328-336, 2017.

[25]. R. Gantawa, N.K. Tamrakar, "Analysis of sediment abrasion potential in hydro turbines by studying fine sediments from the Budhi Gandaki-Trishuli River of Nepal," Journal of Nepal Geological Society, vol. 58, pp. 29-38, 2019.

[26]. M. Kjeldsen, "Diploma Thesis," Norwegian Institute of Technology, 1991.

[27]. M. Knutsen, NTNU, Norway, 1997.

[28]. G.M. Wood, L.K. Knudsen, F.G. Hammitt, "Cavitation damage studies with rotating disc in water," Journal of Basic Engineering, pp. 98-110, 1967.

[29]. A. Shima, H. Tomaru, A. Ihara, N. Miura, "Cavitation damage study with a rotating disk at the high peripheral velocities," Journal of Hydraulic Research, vol. 30, no. 4, pp. 521-538, 1992.

[30]. B. Mann, "Boronizing of cast martensitic chromium nickel stainless steel and its abrasion and cavitation-erosion behavior," Wear, vol. 208, pp. 125-131, 1997.

[31]. B. Mann, "High-energy particle impact wear resistance of hard coatings and their application in hydroturbines," Wear, vol. 237, no. 1, pp. 140-146, 2000.
[32]. B. R. Karnikar, H. P. Neopane and B. S. Thapa, "Development of rotating disc apparatus for test of sediment-induced erosion in Francis runner blades," Wear, vol. 306, no. 1-2, p. 119-125, 2013.

[33]. B. Thapa, P. Chaudhary, O.G. Dahlhaug, P. Upadhyay, "Study of combined effect of sand erosion and cavitation in hydraulic turbines," in International Conference on Small Hydropower-Hydro Sri Lanka, Sri Lanka, 2007.

[34]. A. KC, B. Thapa and Y. H. Lee, "Transient numerical analysis of rotorestator interaction in a Francis turbine," Renewable Energy, vol. 65, pp. 277-235, 2014.

[35]. N. Acharaya , C. G. Kim, B. Thapa and Y. H. Lee, "Numerical analysis and performance enhancement of a cross-flow hydro turbine," Renewable Energy, pp. 1-8, 2015.

[36]. I. b. Celik, U. Ghia, P. J. Roache, C. J. Freitas, H. Coleman and P. E. Raad, "Procedure for Estimation and Reporting of Uncertainty Due to Discretization in CFD applications," Journal of Fluids Engineering, vol. 130, no. 7, pp. 07800110780014, 2008.

\section{Cite this article as :}

Oblique Shrestha, Hari Prasad Neopane, BholaThapa, Young-Ho Lee, Aman Kapali, "Rotating Disc Apparatus and its application to estimate sediment erosion in Hydro turbines", International Journal of Scientific Research in Science and Technology (IJSRST), Online ISSN : 2395-602X, Print ISSN : 23956011, Volume 8 Issue 6, pp. 348-358, NovemberDecember 2021. Available at doi : https://doi.org/10.32628/IJSRST218616 Journal URL : https://ijsrst.com/IJSRST218616 